\title{
An Audit of Routine Chest X-ray Done During Pre-employment Medical Screening in South-Western Nigeria
}

\author{
Anselm Ejike Chukwuani ${ }^{1}$, Abimbola Osanaiye ${ }^{2}$, Obinna Franklin Eneje ${ }^{3}$, \\ David Oselumenosen Omiyi ${ }^{4}$ \\ ${ }^{1}$ Department of Radiology, Reddington Hospital, Lagos, Nigeria \\ ${ }^{2}$ Department of Radiology, Olabisi Onabanjo University Teaching Hospital, Sagamu, Nigeria \\ ${ }^{3}$ Department of Radiology, Garki General Hospital, Abuja, Nigeria \\ ${ }^{4}$ Department of Radiation Biology, Radiotherapy, Radiodiagnosis and Radiography, College of Medicine, University of Lagos, Lagos, \\ Nigeria
}

Email address:

osanaiyeabimbola@gmail.com (A. Osanaiye)

\section{To cite this article:}

Anselm Ejike Chukwuani, Abimbola Osanaiye, Obinna Franklin Eneje, David Oselumenosen Omiyi. An Audit of Routine Chest X-ray Done During Pre-employment Medical Screening in South-Western Nigeria. Central African Journal of Public Health.

Vol. 3, No. 4, 2017, pp. 51-54. doi: 10.11648/j.cajph.20170304.13

Received: June 10, 2017; Accepted: June 30, 2017; Published: August 24, 2017

\begin{abstract}
Routine pre-employment chest radiography is one of the examinations performed to assess the medical fitness of prospective employees in many establishments around the world. It is also used to ensure that prospective employees can perform their jobs safely without placing co-workers and others at potential health risk by ruling out the existence of chronic infectious pulmonary diseases like tuberculosis. Despite these focused goals, there are concerns over poor positive result yield, associated unnecessary exposure to ionizing radiation and wastage of economic resources linked to pre-employment chest $\mathrm{x}$ ray. This study aimed to audit the reports of pre-employment chest radiographs, documented associated radiological findings and subsequently examined the clinical relevance or otherwise of this practice in the locality under study. The records of 725 patients, who had underwent pre-employment chest x-rays between January 2014 and December 2016 in three foremost teaching hospitals in South-western Nigeria, were retrospectively reviewed. All findings were documented including abnormalities 'flagged' as clinically-significant by the radiologists' reports irrespective of the severity or the effect of the abnormality on the employment outcome of the individual. The results show that majority of the patients referred for preemployment chest $\mathrm{x}$-ray presented with normal radiological findings $(\mathrm{n}=687,94.8 \%)$. The significant abnormal findings $(\mathrm{n}=$ $38,5.2 \%)$ were chronic cardiovascular disorder $(\mathrm{n}=15,2.0 \%)$, followed by chronic lung disease $(\mathrm{n}=18,2.5 \%)$ and finally skeletal abnormality $(\mathrm{n}=5,0.7 \%)$. Individuals 25 years and below presented with no abnormal findings while abnormal findings are found in subjects in the age range of 26-30 years and above. This audit has shown that chest radiography has little or no clinical relevance in routine pre-employment medical screening of physically healthy and asymptomatic prospective employees. Therefore, chest radiography should be restricted to individuals with clinical findings suggestive of cardio-thoracic disorders during pre-employment medical screening.
\end{abstract}

Keywords: Human Resources, Medical Fitness, Chest Radiography, Pulmonary Tuberculosis

\section{Introduction}

In many establishments around the world, routine preemployment chest radiograph is performed to assess the medical fitness of prospective employees [1,2]. Nigeria, where pre-employment chest radiograph is routinely done in many large private as well as government owned facilities, is not an exception in this trend [3]. The second rationale for pre-employment chest $\mathrm{x}$-ray is to ensure that prospective employees can perform their jobs safely without placing co- 
workers and others at potential health risk by ruling out the existence of chronic infectious pulmonary diseases like tuberculosis [4, 5]. Despite these focused goals, there has been a lot of discussion regarding the usefulness or otherwise of routine chest radiographs as part of screening of prospective employees, with some studies concluding in favour and others against such practice [1, 3, 4-6]. Critics have cited the often clinically-insignificant findings flagged by this screening as one of the drawbacks of this practice [3]. The required follow-up or clearance for these findings can delay employment, result in the rejection of an otherwise healthy candidate, divert resources and cause unnecessary expenses $[1,4]$. There are also concerns over the unnecessary exposure to ionizing radiation and wastage of limited economic resources in already under-funded health care systems found in sub-Saharan Africa [1]. On the hand, it has also been argued that pre-employment chest radiography is not only beneficial to the candidate but also a means of addressing issues of public health by contributing in the fight against the spread of chronic infectious diseases [4-6]. To the best of the researchers' knowledge, a comprehensive audit to evaluate the clinical relevance of this pre-employment clinical examination has not been performed in this part of Nigeria. Consequently, this study aimed to audit the reports of pre-employment chest radiographs, document findings and subsequently examine the clinical relevance or otherwise of this practice.

\section{Methods}

This non-experimental study was carried out in three foremost teaching hospitals in South-western Nigeria. The records of 725 patients who has underwent pre-employment chest X-rays between January 2014 and December 2016 were retrospectively reviewed. The hospital medical records of patients who underwent a pre-employment medical check-up were collected and reports of chest radiographs were reviewed after institutional ethical approval for human research was granted for the research. The radiographs were acquired using standard techniques for chest radiography by radiographers in the institution. Only postero-anterior views were obtained. All findings were documented including abnormalities 'flagged' as clinically-significant by the radiologists' reports irrespective of the severity or the effect of the abnormality on the employment outcome of the individual. Data collected were statistically analyzed using Statistical Package for Social Sciences software (SPSS v. 24).

\section{Results}

The results illustrate that out of the 725 subjects studied, $37 \%$ of them were males while $63 \%$ were females. It also shows that greatest percentage of subjects are between the age range of $26-30$ years $(n=280,38.6 \%)$ while the least percentage were observed in subjects aged 46 years and above $(n=18,2.4 \%)$ as depicted in Table 1 .
Table 1. Distribution of patients' age according to sex.

\begin{tabular}{llll}
\hline Age (yrs) & Male & Female & Frequency \\
\hline$\leq 20$ & 15 & 33 & $48(6.62 \%)$ \\
$21-25$ & 40 & 185 & $225(31.03 \%)$ \\
$26-30$ & 130 & 150 & $280(38.62 \%)$ \\
$31-35$ & 43 & 46 & $89(12.28 \%)$ \\
$36-40$ & 23 & 21 & $44(6.07 \%)$ \\
$41-45$ & 8 & 13 & $21(2.9 \%)$ \\
$46-50$ & 5 & 4 & $9(1.24 \%)$ \\
$>50$ & 1 & 8 & $9(1.24 \%)$ \\
TOTAL & 265 & 460 & $725(100 \%)$ \\
\hline
\end{tabular}

Table 2 shows that majority of the patients presented with normal radiological findings $(\mathrm{n}=687,94.8 \%)$. The significant abnormal clinical findings are chronic cardiovascular disorder $(\mathrm{n}=18,2.5 \%)$, followed by chronic lung disease $(\mathrm{n}=15,2.0 \%)$ and finally skeletal abnormality $(\mathrm{n}=5,0.7 \%)$.

Table 2. Distribution of findings on chest radiographs.

\begin{tabular}{lll}
\hline Radiological Findings & Frequency & Percentage (\%) \\
\hline Normal Radiograph & 687 & 94.8 \\
Chronic Pulmonary Disease & 18 & 2.5 \\
Chronic Cardiovascular Disorder & 15 & 2.0 \\
Thoracic Cage Abnormality & 5 & 0.7 \\
Total & 725 & 100 \\
\hline
\end{tabular}

Individuals 25 years and below presented with no abnormal findings while abnormal findings are found in subjects in the age range of 26-30 years and above. Patients within the 26-30 years have the highest frequency and also have the highest cases of abnormal findings (Table 3 ).

Table 3. Age distribution of the radiological findings.

\begin{tabular}{lll}
\hline Age & Normal Findings & Abnormal Findings \\
\hline$\leq 20$ & 48 & - \\
$21-25$ & 225 & - \\
$26-30$ & 263 & 17 \\
$31-35$ & 88 & 1 \\
$36-40$ & 37 & 7 \\
$41-45$ & 11 & 8 \\
$46-50$ & 7 & 2 \\
$>50$ & 6 & 3 \\
Total & 687 & 38 \\
\hline
\end{tabular}

\section{Discussion}

A chest $\mathrm{x}$-ray, the most commonly performed radiological investigation, is referred to as "routine" when it is ordered and performed in the absence of a clear clinical indication. In the light of proper indication, its use and importance cannot be overemphasized [5]. On the other hand, its use for routine health examinations; preadmission, preoperative, preemployment and lung cancer screening has long been a source of intense controversy [1-6].

In this audit, chest $\mathrm{x}$-ray findings were classified into normal findings and abnormal findings. Normal findings were reported on radiographs that were completely deviod of chest radiological abnormalities of the lungs, heart and bony ribcage. On the other hand, abnormal radiological findings 
included blunting of the costeprenic angles, cardiomegaly, unfolding of the aorta, increase in linear shadows in the lungs suggestive of bronchopneumonia, opacities (multifocal) in the lungs suggestive of pulmonary tuberculosis [7]. The results show that majority of the patients referred for preemployment chest $\mathrm{x}$-ray presented with normal radiological findings $(\mathrm{n}=687,94.8 \%)$. The most common and significant abnormal findings $(\mathrm{n}=38,5.2 \%)$ were chronic cardiovascular disorder $(\mathrm{n}=15,2.0 \%)$, followed by chronic lung disease $(\mathrm{n}=18,2.5 \%)$ and finally skeletal abnormality $(\mathrm{n}=5,0.7 \%)$. Several previous studies in other regions of the world have reported nearly the same low percentage of abnormal findings as reported in this study. In an African study covering several institutions over a period of 5 years, only $7 \%$ of pre-employment radiographs showed abnormalities [8]. Tigges et al [9] reported that a mere $1.17 \%$ $(n=15)$ chest radiographs showed major abnormalities. Fourteen of the 15 findings of major abnormalities (lung nodules, mass, atelectasis, and mediastinal lymphadenopathy) proved to be false-positives. No disease requiring treatment was diagnosed as a result of radiographic findings in a population of 1282 subjects. The above researchers were of the opinion that this aspect of preemployment medical screening should be discontinued. Cockroft [10] in his study noted that the main rationale of pre-employment chest $\mathrm{x}$-ray is to detect cases of pulmonary tuberculosis but this routine pre-employment chest radiography is not an effective way of doing this. In another study done in South-western Nigeria, Ogbole et al [11] conducted an audit of 1021 radiographs done during preadmission medical screenings for university students and found that only $41(4 \%)$ of the 1021 young adults had an abnormality detected at chest radiography.

The most common pulmonary lesion detected in this study is pulmonary tuberculosis (TB). Tuberculosis continues to be a pressing public health problem in developing nations [3]. Lee et al [12] showed tuberculosis and cardiomegaly as the commonest findings in their study. In this study, individuals with radiographic findings suggestive of $\mathrm{TB}$ and other cardio-vascular conditions were referred for follow-up. Unfortunately, the subsequent clinical data were not available for this study.

This audit also shows no abnormal findings was found in subjects aged 25 years and below calling into question the clinical relevance of exposing these young adults to ionizing radiation in the first place and wasting resources in the process as well. As aforementioned, 38 of the 725 subjects studied had abnormal chest findings. If the costs of the radiological examinations were estimated by using 2016 price estimate for the cost of a chest $\mathrm{x}$-ray in a typical public teaching hospital, the 725 radiographs would cost approximately three million Nigerian naira ( $\$ 3,000,000.00)$. The cost effect is that in comparison, only approximately one hundred and fourteen thousand Nigerian naira $(\$ 114,000.00)$ for the 38 radiographs screened out clinically-significant lesions.

Although the radiation dose one is exposed to during a chest radiograph is fairly low $(0.02 \mathrm{mSv})$ [3], this is unnecessary radiation for the large majority of individuals given low rate of diagnostic yield. Our findings are in line those of other studies which have also shown the low rate of diagnostic yield of routine chest radiography in mass routine chest $x$-ray $[13,14]$ even in patients with positive purified protein derivative tests [15]. Considering the large numbers of prospective subjected to chest rays throughout the country, it would add significantly to the collective radiation dose of a given population. Secondly, the time cost for the chest radiography and its interpretation, from patient reception to report dissemination, was not considered in this study. The scale of resource wastage will be significantly high when all these factors are evaluated on a national scale. To encapsulate, Loyhiya et al [1] reported that this pratice causes unwarranted radiation exposure, gave false sense of security regarding workers risk management, unnecessary and wasteful.

\section{Conclusion}

This audit found that chest radiography has little or no clear justification in routine pre-employment medical screening of physically healthy and asymptomatic prospective employees in locality studied given the low rate of diagnostic yield, the collective radiation dose given to a population and the wastage of scarce economic resources involved in this practice, with a particular reference to resource-limited settings like sub-Saharan African's. Therefore, it is recommended that chest radiography should be restricted to individuals with clinical findings suggestive of cardio-thoracic disorders during pre-employment medical screening in the locality studied.

\section{Limitations/Conflicts of Interest}

Follow-up data of patients with abnormal findings on chest $\mathrm{x}$-ray were not available for inclusion in this audit.

The authors have no conflicts of interest.

\section{References}

[1] Lohiya GS, et al., et al. The futility of universal preemployment chest radiographs. J Natl Med Assoc 2006; 98: 2019-23.

[2] Samuel J, Gibikote S, and Henry K. The routine preemployment screening chest radiograph: Should it be routine? Indian J Radiol Imaging. 2016 Jul-Sep; 26(3): 402-404.

[3] Ogbeide $\mathrm{O}$ and Adeyekun A, An audit of 3859 preadmission chest radiographs of apparently healthy students in a Nigerian Tertiary Institution. Niger Med J. 2011 Oct-Dec; 52(4): 260262.

[4] Serra C, Rodriguez MC, Delclos GL, Plana M, Gómez López LI, Benavides FG. Criteria and methods used for the assessment of fitness for work: a systematic review. Occup Environ Med 2007; 64: 304-12. 
[5] Carter T. The application of the methods of evidence based practice to occupational health. Occup Med (Chic Ill) 2000; 50: 231-6.

[6] Franco G. Evidence-based decision making in occupational health. Occup Med (Chic Ill) 2005; 55: 1-2.

[7] Kumar V, Abdul K, Richard N. Robbins Basic Pathology ( $8^{\text {th }}$ ed.) Saunders Elsevier. 2007 pp. 516-522.

[8] Kouamé N, Ngoan-Domoua AM, Konan AN. Systematic chest radiography during pre-employment check-up. African Journal of Respiratory Medicine. 2012; 7: 15-8.

[9] Tigges S, Roberts DL, Vydareny KH, Schulman DA. Routine chest radiography in a primary care setting. Radiology. 2004; 233: $575-8$.

[10] Cockroft A. Chapman S. Insal C. Soper P. Kennard Y, Hollis C. Tuberculin reactivity in new employees in London Health District 1998; 43: 834.
[11] Ogbole GI, Agunloye AM, Adeyinka AO. Are routine chest radiographic examinations of students in Nigerian Universities still relevant? An imaging perspective, Journal of Medicine and Medical Sciences. 2014: 3(12) 780-783.

[12] Lee TK, Low CH. Routine roentgenography on 4,036 health screening patients in a private hospital out-patient clinic. Singapore Med J. 1986; 27: 18-25.

[13] Chaturvedi N, Cockcroft A (1992). Tuberculosis screening in health service employees: who needs chest X-rays? Occup Med (Lond). 42: 179-82.

[14] Eisenberg RL, Pollock NR (2010). Low yield of chest radiography in a large tuberculosis screening program. Radiology. 256: 998-1004.

[15] Adeyekun AA, Egbagbe EE, Oni OA (2010). Contact tracing/preemployment screening for pulmonary tuberculosis: should positive Mantoux test necessitates routine chest X-ray? Ann Afr. Med. 3: 159-63. 